\title{
Acute Pancreatitis between Practice and Recommendations
}

\section{Type of article: Original}

\author{
Boumediene Elhabachi, Morsli Doulat, Abderrahman Blaha, Soumia Zaouag, Hassan Cheheb \\ Faculty of medicine University of Sidi Bel Abbes, Algeria \\ CHU Dr Hassani A.E.K, Algeria
}

\begin{abstract}
.
Background: Acute inflammation of the pancreas, acute pancreatitis (AP) shows an increasing incidence in the world as well as in Algeria. However, lethality and mortality are decreasing, mainly due to recommendations from Atlanta, the International Pancreatology Association, and the American Pancreatology Association. The purpose of this work was to analyze the management of AP in the general surgery department of the UHC of Sidi Bel Abbes.

Method: In a retrospective study, 100 acute pancreatitis cases admitted to general surgery between January 2017 and December 2019 were analyzed.

The abdominal scanner was systematic at the admission. The rate of lipasemia, when greater than 3 times the normal one, allowed, in association with the evocative pain, to make the diagnosis. The severity of AP was assessed using the Balthazar score. An MRI was requested when the scanner was inconclusive, to look for an etiology and / or possible complications. Seventy-nine (79\%) patients received broad-spectrum antibiotic therapy and diet was systematic.

Results: We have transmitted the recommendations of scholar societies to the various specialists and the management of AP is currently more unified and more effective. Scanner is no longer systematic in the early phase. Antibiotic therapy is no longer administered without biological evidence. Enteral nutrition is now possible.

Conclusion: We were able to reach the goal of reducing hospitalization and scanning requests. A further analysis of 100 other PA files is planned to confirm the obtained results.

Keywords: Acute pancreatitis; Atlanta conferences; Associations of pancreatology.

Corresponding author: Boumedien Elhabachi, Faculty of medicine University of Sidi Bel Abbes, Algeria.

Email: b.elhabachi@yahoo.fr

Received: July 12 2020. Reviewed: August 17 2020. Accepted: October 29 2020. Published: November 112020.

Medical Technologies Journal subscribes to the principles of the Committee on Publication Ethics (COPE).

Screened by iThenticate..๑2017-2020 KNOWLEDGE KINGDOM PUBLISHING.
\end{abstract}

\section{Introduction}

Acute pancreatitis (AP) is an acute inflammation of the pancreas, clinically characterized by acute abdominal pain and a serum elevation of pancreatic enzymes. In view of current knowledge, acute pancreatitis, especially in its severe form, must be perceived as a "sepsis-like syndrome" characterized by a systemic inflammatory response syndrome (SIRS) [1]. The incidence of AP continues to grow, especially in the USA and Europe, even if there are variations according to regions and countries for the same continent [2-3]. It is the same in Algeria, where the incidence of AP at Sidi Bel Abbes University Hospital Center has quadrupled throughout 20 years. Formerly a surgical emergency, AP is now considered as a resuscitation emergency, requiring days of hospitalization [4-6] at very high cost [4].

However, if the incidence of AP increases, lethality [3] and mortality [7] are decreasing compared to historical data, although the mortality remains high, between 1 and 5\% [4]. This is a life-threatening emergency whose management is multidisciplinary, provided by a specialized team in pancreatology, within a accordingly equipped center. Only under these conditions, mortality from severe forms will be reduced by more than $27 \%$, the length of hospital stay shortened and complications better managed. Effective communication between specialists is essential. The team stakeholders must use the same language in order to avoid any confusion that is sometimes a source of fatal misinterpretation. The Atlanta 
conference of 1992, updated in 2012, responds to this imperative by proposing a language that every physician must use [8-9]. The International Association of Pancreatology (IAP) and American Pancreatology Association (APA) have made recommendations [10] as to support the AP.

Our present work aims to analyze the management of AP in the general surgery department of Sidi Bel Abbes UHC, compared to these recommendations.

\section{Subjects and methods}

We carried a retrospective survey in order to analyze the files of the last 100 acute pancreatitis admitted to the general surgery department, between January 2017 and December 2019, after their transfer from medical and surgical emergencies.

Inclusion criteria: Acute pancreatitis in subjects of both sexes over 16 years of age.

Exclusion criteria: Patients under the age of 16 and postoperative acute pancreatitis.

Our purpose was to verify whether the care procedures have complied with international recommendations, those of (IPA), (APA) and the data from the 2012 Atlanta conference.

About positive diagnosis: After collecting some demographic data, our patients underwent, upon admission, an interrogation, and a series of examinations.

- The questioning looked for the notion of alcoholism, metabolic disorders, and drug intake.

- The clinical examination specified the pain and its semiological characteristics as well as the presence of vomiting. Body temperature, heart rate, and blood pressure were measured.

- Complementary examinations were based on:

- Biological data with mainly the assay of lipasemia, a blood count, and kidney function.

- Medical imaging: in order to assess the severity of the attack, an abdominal computed tomography (ACT) was routinely ordered after the $48^{\text {th }}$ hour in 12 patients, the $72^{\text {nd }}$ hour in 77 patients and the $92^{\text {nd }}$ hour in only 11 patients. The severity of the acute pancreatitis was assessed according to the Balthazar classification. A magnetic resonance imaging (MRI) allowed the classification of acute pancreatitis of our patients; it was requested in 20 of them: when the CT was inconclusive (8 patients), to look for an etiology (7 patients) and possible complications (5 patients).

- Assessment of respiratory function.

About etiological diagnosis: It was clarified after careful questioning and clinical examination.

\section{Results}

In our series, more than $50 \%$ of AP occurred in people over the age of 50. There is a male predominance for patients over the age of 31 , an inverted rate for patients aged from 16 to 30 .

Clinically, pain dominated the picture in $82 \%$ of the cases. It was very evocative of a pancreatic origin with its intensity, its epigastric site, and its transfixing character. Vomiting was reported in $40 \%$ of cases. The interrogation found the notion of chronic alcoholism in 16 patients, metabolic disorders in 8 patients, 
medicament intake mainly for arterial hypertension, diabetes, and thyroid disease in 10 patients. A biliary cause was found in $66 \%$ of the cases (history of hepatic colic, sub-jaundice $(06 \%)$, biliary surgery $(10 \%)$. Acute iatrogenic pancreatitis post RECP (retrograde endoscopy cholangiopancreatography) was found in $2 \%$ of cases. Biologically, the diagnosis was posed when lipasemia value was greater than 3 times the upper limit of normal and it was the case in 60 patients. ACT examination allowed assessing the severity of acute pancreatitis according to the Balthazar classification: 16 cases were found at stage A; 5 cases at stage B; 32 cases at stage C; 11 at stage D: and 36 at stage E.

Regarding MRI, the study of the files made it possible to classify the AP of our survey into mild AP in 49 cases, moderately severe in 27 cases and severe AP in 24 cases.

Upon admission, kidney dysfunction is reported in 15 patients, tachycardia in 10 patients, hypotension in 12 and hyperthermia in 34 patients. Ten patients had a disturbance in respiratory function. Hyperleukocytosis is noted in 63 patients.

After the $48^{\text {th }}$ hour, renal function was disturbed in nine patients; tachycardia was present in 09 patients, hypotension in 08 patients and hyperthermia in 38 patients. Eleven patients presented with disturbed respiratory function. Hyperleukocytosis is noted in 49 patients. According to records, organ failure was held up when a disruption of function was found.

In retrospect, we also found that a Broad-spectrum antibiotic therapy was prescribed in 79 patients, and a nasogastric tube inserted in 21 patients. A diet of 04 to 10 days was systematic in the patients. For AP B, 30 cholecystectomies were performed within 6 to 8 weeks following discharge from the service.

\section{Discussion}

Analysis of the files reveals that the care of APs varies widely depending on the on-call teams.

According to the Atlanta conference, the onset of acute pancreatitis is defined by the time of onset of abdominal pain, not the time of admission to hospital. In almost all of the files, confusion was noted between the actual start of the crisis and the time of admission.

This concept is important when transferring a patient to another health center. The patient card must specify the time of onset of pain and the time of admission with all the collected parameters and medical information [8]. Rightly, amylasemia was not requested, as it is not specific to pancreatic disease.

The Atlanta conference defines the diagnosis of AP as the presence of at least two of the following three diagnostic criteria [8,11 and12]:

- Evocative abdominal pain (acute pain with a sudden onset, epigastric, permanent and transfixing radiating to the back). Lipasemia (or amylasemia) three times the upper limit of normal.

- Lipasemia (or amylasemia) three times the upper limit of normal.

- Characteristic signs on imaging (CT scan with injection, more rarely on MRI or abdominal ultrasound).

Abdominal CT was systematic in all patients, although it is no longer indicated at admission, neither for diagnostic purposes nor to assess the severity of the AP.

On the other hand, it is indicated during the early phase when there is a doubtful diagnosis or a suspected complication, for monitoring the evolution as well as for etiological research. 
During the early period, there is no clinico-radiological parallelism; therefore, we should focus exclusively on clinical and biological parameters. It is only in the presence of disturbances in the early phase that imaging will be judicious to look for pancreatic or locoregional complications.

According to the Atlanta conference, the initial assessment (clinical, biology, chest radiography, and systematic abdominal ultrasound) identifies three situations:

- Low severity AP with low risk of necrosis and death: The abdominal CT scan is not necessary if the clinical course remains favorable within 72 hours. It is not systematic and will not be requested in case of mild AP without a diagnostic or etiological problem. CT should not be performed systematically in mild recurrent AP without seriousness, especially in a patient known to the department. And in total, this examination will not be requested in the absence of complications.

- Intermediate or high severity AP: the risk of necrosis is possible and the risk of death is not negligible. The scanner should be done within 5-7 days. Intensive therapeutic measures must be started quickly with a multidisciplinary team.

- There are signs of seriousness, but the diagnosis is questionable. There is an indication to scan as soon as possible in less than 48 hours looking for an accurate diagnosis.

The scan should not be done too early or too often without justification. In fact, a CT scan with injection can worsen AP with potential nephrotoxicity. In addition, its repetition exposes to a significant irradiation. We must be careful with a young person with hereditary PA.

However, this examination will be necessary with severe or moderately severe AP if there is a deterioration of the clinical condition or no response to a wellconducted treatment. Otherwise, it will be done as late as possible.

The Balthazar score [13] was used in all patients by the radiologist to assess the severity of the AP, which is no longer retained by the recommendations of learned societies. Especially since it was modified for the first time by its author [14-15] to include the necrosis of the parenchyma evaluated as a percentage, and a second time when it was said mCTSI: the latter takes into account the extra pancreatic complications [16], with a better correlation with the severity of AP [17].

We have found that antibiotic therapy has been prescribed in 79 patients as a preventive measure to face hyperthermia or leukocytosis, while learned societies only recommend antibiotic therapy if there is a proven infection. Prophylaxis antibiotic is not systematic in patients even with severe AP [18-19] including those with sterile necrosis [20-21]. This antibiotic therapy is also not justified in the face of a simple feverish state, high CRP or hyperleukocytosis [19, and 22-25], the major risk being the selection of germs, especially fungal ones, which is damaging for the patient and for the hospital, without actually preventing infection or reducing mortality [24].

In the face of a suspected clinical or radiological infection [18], a sample must prove it. It will be done at the collection level and or at the periphery. Currently, an assay of procalcitonin, the blood level of which rises in case of infection, has been proposed for the diagnosis of infected necrosis [18].

All our patients were put on a diet, while oral feeding can be resumed in mildly severe AP as soon as the pain subsides and when the markers of inflammation improve [1]. All patients with severe AP or predictive factors of severity should be placed on artificial nutrition. Indeed, enteral nutrition is clearly superior to 
parenteral one for preventing organ failure [26], systemic and surgical interventions infection and even for reduction of mortality.

Enteral nutrition can be administered by the naso-jejunal way and advantageously by the nasogastric way [1] (which does not require endoscopy or anesthesia).

Parenteral nutrition will only be administered if support is necessary when the naso-jejunal way is not tolerated. This diet must be started within 24 to 48 hours to prevent bacterial translocation and therefore infection from necrosis, noninfectious complications, mortality as well as the length of hospitalization [27]. In case of parenteral feeding, the first opportunity must be taken to switch to enteral feeding.

For mild biliary pancreatitis, cholecystectomy and / or sphincterotomy must be performed during the same hospitalization. Indeed, recurrence after one month is estimated at $20 \%$ and can sometimes be serious.

\section{Conclusion}

Acute pancreatitis is a life-threatening emergency whose management is multidisciplinary. However, mortality from severe forms can be reduced by $27 \%$ in a well-equipped specialized center. Praying practices in our department have significantly improved since we communicated our remarks to all acute pancreatitis staff and they have been meticulously followed. Thus, a marked reduction in the length of hospitalization and requests for scanners was noted. A subsequent analysis of one hundred other cases of acute pancreatitis would be necessary to confirm the obtained results.

\section{Acknowledgement}

We would like to thank the general surgery team for allowing us the access to the medical records in order to achieve this analysis.

\section{Conflict of interest statement}

We certify that there is no conflict of interest with any financial organization in the subject matter or materials discussed in this manuscript.

\section{Authors' biography}

Professor Boumédiène ELHABACHI: Gratuated in senology, cancerology and repair surgery. As a lecturer professor, I work hard and steadily to put implement any new techniques or actions within our hospital structures, that would allow us to open up to the future offered by onco-genetic advances and technologies of medical imagery. This will largery benefit the patients of tomorrow.

Doctor Hassan CHEHEB: Gratuated in general surgery. Assistant master, particularly invested in hepato-biliary cancerology, we are joining efforts to solve 
the problems of a future multidisciplinary management of our patients in a specific socio-economic and cultural context.

Doulat Morsli: Resident physicians general surgery faculty of medecine of Sidi Bel Abbes, Algeria.

Abderrahman Blaha: Resident physicians general surgery faculty of medecine of Sidi Bel Abbes, Algeria.

Soumia Zaouag: Resident physicians general surgery faculty of medecine of Sidi Bel Abbes, Algeria.

\section{References}

[1] Rinninella, E., et al., Nutritional support in acute pancreatitis: from physiopathology to practice. An evidence-based approach. Eur Rev Med Pharmacol Sci, 2017. 21(2): p. 421-432.

[2] Banks, P.A., Epidemiology, natural history, and predictors of disease outcome in acute and chronic pancreatitis. Gastrointest Endosc, 2002. 56(6 Suppl): p. S226-30. https://doi.org/10.1016/S0016-5107(02)70016-3

[3] Yadav, D. and A.B. Lowenfels, Trends in the epidemiology of the first attack of acute pancreatitis: a systematic review. Pancreas, 2006. 33(4): p. 323-30. https://doi.org/10.1097/01.mpa.0000236733.31617.52 PMid:17079934

[4] Krishna, S.G., et al., The Changing Epidemiology of Acute Pancreatitis Hospitalizations: A Decade of Trends and the Impact of Chronic Pancreatitis. Pancreas, 2017. 46(4): p. 482-488. https://doi.org/10.1097/MPA.0000000000000783 PMid:28196021 PMCid:PMC5435121

[5] Peery, A.F., et al., Burden of gastrointestinal disease in the United States: 2012 update.

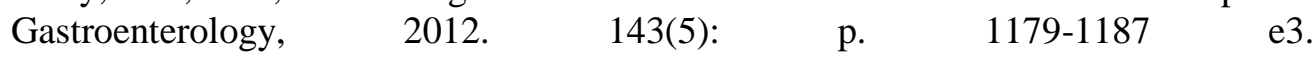
https://doi.org/10.1053/j.gastro.2012.08.002 PMid:22885331 PMCid:PMC3480553

[6] Lowenfels, A.B., P. Maisonneuve, and T. Sullivan, The changing character of acute pancreatitis: epidemiology, etiology, and prognosis. Curr Gastroenterol Rep, 2009. 11(2): p. 97-103. https://doi.org/10.1007/s11894-009-0016-4 PMid:19281696

[7] Roberts, S.E., et al., The incidence and aetiology of acute pancreatitis across Europe. Pancreatology, 2017. 17(2): p. 155-165. https://doi.org/10.1016/j.pan.2017.01.005 PMid:28159463

[8] Banks, P.A., et al., Classification of acute pancreatitis--2012: revision of the Atlanta classification and definitions by international consensus. Gut, 2013. 62(1): p. 102-11. https://doi.org/10.1136/gutjnl-2012-302779 PMid:23100216

[9] Bradley, E.L., 3rd, A clinically based classification system for acute pancreatitis. Summary of the International Symposium on Acute Pancreatitis, Atlanta, Ga, September 11 through 13, 1992. Arch Surg, 1993. 128(5): p. 586-90. https://doi.org/10.1001/archsurg.1993.01420170122019 PMid:8489394

[10] IAP/APA evidence-based guidelines for the management of acute pancreatitis. Pancreatology, 2013. 13(4 Suppl 2): p. e1-15. https://doi.org/10.1016/j.pan.2013.07.063

[11]Bollen, T.L., et al., A comparative evaluation of radiologic and clinical scoring systems in the early prediction of severity in acute pancreatitis. Am J Gastroenterol, 2012. 107(4): p. 612-9. https://doi.org/10.1038/ajg.2011.438 PMid:22186977

[12] Sarr, M.G., et al., The new revised classification of acute pancreatitis 2012. Surg Clin North Am, 2013. 93(3): p. 549-62. https://doi.org/10.1016/j.suc.2013.02.012 PMid:23632143

[13]Balthazar, E.J., et al., Acute pancreatitis: prognostic value of CT. Radiology, 1985. 156(3): p. 767-72.https://doi.org/10.1148/radiology.156.3.4023241 PMid:4023241

[14] Balthazar, E.J., P.C. Freeny, and E. vanSonnenberg, Imaging and intervention in acute pancreatitis. Radiology, 1994. 193(2): p. 297-306. https://doi.org/10.1148/radiology.193.2.7972730 PMid:7972730 
[15] Balthazar, E.J., et al., Acute pancreatitis: value of CT in establishing prognosis. Radiology, 1990. 174(2): p. 331-6. https://doi.org/10.1148/radiology.174.2.2296641 PMid:2296641

[16] Mortele, K.J., et al., A modified CT severity index for evaluating acute pancreatitis: improved correlation with patient outcome. AJR Am J Roentgenol, 2004. 183(5): p. 1261-5. https://doi.org/10.2214/ajr.183.5.1831261 PMid:15505289

[17] Bharwani, N., et al., Acute pancreatitis: the role of imaging in diagnosis and management. Clin Radiol, 2011. 66(2): p. 164-75. https://doi.org/10.1016/j.crad.2010.09.003 PMid:21216333

[18] Leppaniemi, A., et al., 2019 WSES guidelines for the management of severe acute pancreatitis. World J Emerg Surg, 2019. 14: p. 27. https://doi.org/10.1186/s13017019-0247-0 PMid:31210778 PMCid:PMC6567462

[19] Wittau, M., et al., Systematic review and meta-analysis of antibiotic prophylaxis in severe acute pancreatitis. Scand J Gastroenterol, 2011. 46(3): p. 261-70. https://doi.org/10.3109/00365521.2010.531486 PMid:21067283

[20] Forsmark, C.E., S.S. Vege, and C.M. Wilcox, Acute Pancreatitis. N Engl J Med, 2016. 375(20): p. 1972-1981. https://doi.org/10.1056/NEJMra1505202 PMid:27959604

[21] Wu, B.U. and P.A. Banks, Clinical management of patients with acute pancreatitis. Gastroenterology, $2013.2144(6): \quad$ p. $1272-81$. https://doi.org/10.1053/j.gastro.2013.01.075 PMid:23622137

[22] French Consensus Conference on Acute Pancreatitis: Conclusions and Recommendations. Paris, France, 25-26 January 2001. Eur J Gastroenterol Hepatol, 2001. 13 Suppl 4: p. S1-13.

[23] Dellinger, E.P., et al., Early antibiotic treatment for severe acute necrotizing pancreatitis: a randomized, double-blind, placebo-controlled study. Ann Surg, 2007. 245(5): p. 674-83. https://doi.org/10.1097/01.sla.0000250414.09255.84 PMid:17457158 PMCid:PMC1877078

[24] Mazaki, T., Y. Ishii, and T. Takayama, Meta-analysis of prophylactic antibiotic use in acute necrotizing pancreatitis. $\mathrm{Br} \mathrm{J}$ Surg, 2006. 93(6): p. 674-84. https://doi.org/10.1002/bjs.5389 PMid:16703633

[25] Nathens, A.B., et al., Management of the critically ill patient with severe acute pancreatitis. Crit Care Med, 2004. 32(12): p. 2524-36. https://doi.org/10.1097/01.CCM.0000148222.09869.92 PMid:15599161

[26] Al-Omran, M., et al., Enteral versus parenteral nutrition for acute pancreatitis. Cochrane Database Syst Rev, 2010(1): p. CD002837. https://doi.org/10.1002/14651858.CD002837.pub2 $\quad$ PMid:20091534 PMCid:PMC7120370

[27] da Costa, D.W., et al., Staged multidisciplinary step-up management for necrotizing pancreatitis. Br J Surg, 2014. 101(1): p. e65-79. https://doi.org/10.1002/bjs.9346 PMid:24272964 